\title{
ÇİNKO BORAT KATKILI POLİPROPİLEN'İN REOLOJİK ÖZELLİKLERİNİN BELİRLENMESİ
}

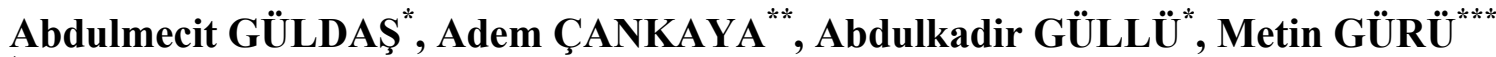 \\ *Gazi Üniversitesi, Teknoloji Fakültesi, İmalat Mühendisliği Bölümü, Teknikokullar/Ankara \\ ${ }^{* *}$ Türkiye Büyük Millet Meclisi, Bakanlıklar Kızılay/Ankara \\ ${ }^{* * *}$ Gazi Üniversitesi, Mühendislik Fakültesi, Kimya Mühendisliği Bölümü, Maltepe/Ankara \\ aguldas@gazi.edu.tr, ademcankaya78@gmail.com, agullu@gazi.edu.tr, mguru@gazi.edu.tr
}

(Geliş/Received: 12.08.2013; Kabul/Accepted: 27.02.2014)

\begin{abstract}
ÖZET
Gerçekleştirilen bu çalışmada, toz haldeki polipropilen (PP) malzemeye ağırlıkça \% 5; \% 7,5; \% 11,25; \% 16,875 ve $\% 25,3125$ oranlarında çinko borat ilave edilerek takviyelendirilmiş polipropilen granülleri üretilmiştir. Çinko borat katkılı polipropilenin granül üretimi esnasında karışıma, oksitlenmeyi önlemek amacıyla \% 0,2 oranında antioksidan olarak maleik anhidrit katılmıştır. Kompozit granül üretildikten sonra ergiyik akış indeksi (EAİ) cihazı kullanılarak takviyelendirilmiş poliproplen'in reolojik özellikleri tespit edilmiştir. Dört farklı yük $(298,2 \mathrm{kPa}, 524 \mathrm{kPa}, 689,5 \mathrm{kPa}$ ve $987,4 \mathrm{kPa})$ ve dört farklı sıcaklık $\left(190{ }^{\circ} \mathrm{C}, 200^{\circ} \mathrm{C}\right.$, $210^{\circ} \mathrm{C}$ ve $220^{\circ} \mathrm{C}$ ) altında yapılan deneylerde malzemelerin EAİ kayma gerilmesi, kayma hızı ve viskozite değerleri elde edilmiştir. Bu çalışmaya göre, artan çinko borat katkı oranına göre viskozite değerinin arttı̆̆ ancak artan sıcaklık ve basınca bağlı olarak viskozitenin azaldığı tespit edilmiştir. Artan sıcaklık ve basınca bağlı olarak EAİ değerinde artış olurken, artan çinko borat katkı oranına göre ise EAİ'de azalma olduğu belirlenmiştir. Ayrıca, kayma hızının artan katkı oranına bağlı olarak azaldığı ancak sıcaklık ve basınç artışı ile birlikte arttığı görülmüştür.
\end{abstract}

Anahtar Kelimeler: Çinko borat takviyeli polipropilen, Reolojik özellikler, Viskozite, Kayma hızı, Ergiyik akış indeksi

\section{DETERMINATION OF RHEOLOGICAL PROPERTIES OF ZINC BORATE REINFORCED POLYPROPYLENE}

\begin{abstract}
In this study reinforced polypropylene granules have been produced by the way zinc borate are added to powder polypropylene material at the rate of $5 \%, 7.5 \%, 11.25 \%, 16.875 \%$ and $25.3125 \%$. To prevent oxidation, at the rate of $0.2 \%$ maleic anhidrit as a antioxidant has been added to PP during the production of zinc borate reinforced polypropylene granule. After composite granule was produced, rheological properties of reinforced polypropylene have been determined by using melt flow index device (MFI). MFI, shear stress, shear rate and viscosity values have been obtained by the experiments that was carried out under four different load $(298.2 \mathrm{kPa}$, $524 \mathrm{kPa}, 689.5 \mathrm{kPa}$ and $987.4 \mathrm{kPa})$ and four different temperature $\left(190{ }^{\circ} \mathrm{C}, 200{ }^{\circ} \mathrm{C}, 210{ }^{\circ} \mathrm{C}\right.$ and $\left.220{ }^{\circ} \mathrm{C}\right)$. According to this study, it has been determined that viscosity value increased depending on zinc borate rate but viscosity decreases depending on increasing temperature and pressure. It was determined that MFI values have been increased depending on increasing temperature and pressure whereas MFI values have been decreased according to increasing zinc borate rate. In addition, it has been seen that shear rate decreases depending on increasing proportion of additive but it increases with the increase of temperature and pressure.
\end{abstract}

Key Words: Zinc borate reinforced polypropylene, Rheological properties, Viscosity, Shear rate, Melt flow index 


\section{GIRIŞ̧ (INTRODUCTION)}

Plastikler, üretim yöntemlerinin çok çeşitli olması, fiziksel ve kimyasal özelliklerinin istenildiği gibi değiştirilebilir olması ve düşük maliyetleri sebebiyle günümüzde konvansiyonel malzemelerin yerini hızla almaktadır. Plastiklerin gittikçe artan bir şekilde kullanılıyor olmaları, gelişen teknolojiye paralel olarak plastik sektörünü de sürekli bir gelişim içine sokmuştur. Plastiklerin, mekanik, 1sıl, elektrik, sürtünme ve aşınma, renklendirme, yanmazlık, ssıya dayanım ve boyutsal kararlılık gibi özelliklerinin artırılması için takviye elemanları ayrıca maliyetlerinin düşürülmesi için ise katkı ve dolgu maddeleri ilave edilmektedir. Literatürde takviye ve katkı elemanı olarak birçok malzeme kullanılmaktadır. Bunlar; cam elyaf, kalsiyum karbonat, metal tozu ve karbon siyahı gibi malzemelerdir. Fakat, bor ve bor bileşikleri içeren takviyeli/katkılı plastik malzemeleri diğer katk1 maddelerine nazaran daha az çalışılmıştır. Çok çeşitli plastik malzeme türü bulunması ve bunlara bor ve bor bileşiklerinin katkı maddesi olarak eklenmesi ile oluşan kompozitin reolojik, mekanik, 1s1l, elektriksel, optik vb gibi birçok özelliğinin nasıl değiştiği konusunda daha çok çalışma yapılması gerekmektedir.

Plastiklerin yapıları gereği üretim aşamasındaki en ufak bir değişiklik bile çok ciddi yapısal değişimlere sebep olmaktadır. Böylece, elde edilen yeni plastiğin birçok fiziksel özelliği değişmektedir. Bu özellikler, plastik içerisine katılan katkı elemanının oranı, boyutu ve yapı içerisindeki özdeş dağılımı ve üretim şekline bağlı olarak değişmektedir. Takviyelendirilmiş plastiklerin kalıplanması ya da şekillendirilmesi sırasında akış özelliklerinin önceden bilinmesi son derece önemlidir. Ayrıca, plastikler metallere göre daha yüksek genleşme katsayılarına sahip olduğundan kalıp ile şekillendirmede çekme oranının da bilinmesi son derece önemlidir. Kalıp tasarlanırken bu çekme oranı kullanılarak kalıp boşluğu oluşturulmaktadır. Böylece belirlenen oranda büyük yapılan kalıp boşluğuna ergimiş plastik malzeme doldurularak şekillendirilir. Ergimiş plastik daha önceden çekme miktarı ve toleransları dikkate alınarak oluşturulmuş kalıp boşluğunda soğuduktan sonra küçülerek istenilen ölçüde plastik parça üretilmiş olur.

Plastiklerin bazı fiziksel özelliklerini değiştirmek için yapısına çeşitli katkı maddeleri katılmaktadır. Literatürde daha önce yapılmış çalışmalara bakıldığında özellikle alev geciktirici özelliğinden dolayı plastik malzemeler içerisine çinko borat $\left(2 \mathrm{ZnO} \cdot 3 \mathrm{~B}_{2} \mathrm{O}_{3} \cdot 7 \mathrm{H}_{2} \mathrm{O}\right.$ ve $\left.2 \mathrm{ZnO} \cdot 3 \mathrm{~B}_{2} \mathrm{O}_{3} \cdot 5 \mathrm{H}_{2} \mathrm{O}\right)$ katılmaktadır [1-5]. Mikron boyutundaki çinko borat parçacıklarının, mükemmel alev geciktirici özelliğinin yanında polimerlerin mekanik özelliklerini de etkilediği belirtilmektedir [1]. $\mathrm{Mg}(\mathrm{OH})_{2}$, talk ve çinko borat katk1 maddeleri belirli oranlarda EVA malzemesi içerisine katılarak kompozitin alev geciktirici özelliği ayrıca viskozite-kayma hızı ilişkisi incelenmiş ve kayma hızı arttıça viskozitenin azaldığı tespit edilmiştir [6]. Köytepe ve arkadaşları ise, polyimid içerisine nano boyuttaki çinko borat parçacıkları ekleyerek malzemenin alev geciktirici özelliğini incelemişlerdir [7]. Polimer içerisine katılan malzemelerin; polimerin reolojik özelliklerini değiştirdiği ve bu değişimde parçacık büyüklüğünün de etkili olduğu belirtilmektedir [8]. Başka bir çalışmada, EVA- $\mathrm{Mg}(\mathrm{OH})_{2}$ içerisine çinko borat katılarak alev geciktirici özelliği ve akış özelliği incelenmiştir [9].

Hammadde üreticileri takviyelendirilmemiş plastiklerin akış özelliklerine ait belirli sıcaklık ve basınç için değer önermektedir. Fakat birçok takviyelendirilmiş plastiklere ait veriler bulunmamaktadır. Gerçekleştirilen bu çalışmada, katkı maddesi olarak belirlenen çinko borat beş farklı oranda polipropilen malzemesine katılarak granül üretilmiştir. Üretilen takviyelendirilmiş polipropilenin reolojik özelliklerinin belirlenebilmesi için endüstride çok sık kullanılan en pratik yöntemlerden biri olan ergiyik akış indeksi cihazı kullanılmıştır. Böylece, bu çalışmada çinko borat katkılı PP malzemesinin ergiyik akış indeksi, viskozite, kayma hızı ve kayma gerilmesi gibi akış parametrelerinin katkı maddesi takviye oranı, sıcaklık ve basınç gibi parametreleri ile değişimi belirlenmiştir.

\section{DENEYSEL YÖNTEMLER (EXPERIMENTAL METHODS)}

Ergiyik akış indeksi (EAI) testi, basit olmakla birlikte, hem uygulanmasının kolaylığı hem de pratik oluşu sebebiyle, plastik malzemelerin sinıflandırılması ve tanımlanmasında sıklıkla kullanılan bir yöntemdir [10-12]. EAİ değeri, özellikle plastik hammadde üreticileri tarafindan plastiklerin fiziksel, kimyasal ve termomekanik özellikleri belirlenirken veya katalog oluşturulurken yoğunluktan sonra verilen en önemli akış özelliği olmuştur $[12,13]$. EAİ testi, önerilen sıcaklık ve yükleme koşulları altında özel olarak belirlenmiş uzunluk ve kesitlerinden geçen, plastik malzemenin kütlesel veya hacimsel miktarın ölçmektedir. Ergiyik akış indeksi akışkanlığı temsil ettiği için malzemenin akış özellikleri hakkında genel bir bilgi vermektedir $[14,15]$. Termoplastikler için test standard, ASTM D1238 ve TS EN ISO 1133 ile tanımlanmıştır $[15,16]$. EAİ test cihazı silindir, piston ve akışın gerçekleştiği standart uç olan burç şeklindeki nozuldan ibarettir.

EAİ test cihazı, Davenport marka test cihazı olup, \pm $0,1{ }^{\circ} \mathrm{C}$ hassasiyetinde ve pistonun hareketi konum sensörü ile tespit edilmektedir. EAİ deney cihazındaki akış ağzı kalıbı (nozul) safirden, plastik malzemenin ergitildiği silindir ise, polimerlerle kimyasal reaksiyona girmeyen ve korozyon etkisi oluşturmayan malzemeden üretilmiștir. Granül haldeki PP 
malzemesi, standardına (3-8 g) uygun olarak $5 \mathrm{~g}$ kullanılmıştır. Kademeli olarak kalıba doldurulan bu plastik malzeme, özel bir baskı aparatı ile silindir içerisinde sıkıştırılarak arada kalan boşluklar en aza indirilmektedir. ASTM D 1238 ve TS EN ISO 1133'e göre akış özelliklerinin sağlıklı olarak ölçülebilmesi için plastik malzeme, isıtıcılar vasıtasıyla 5 dakika süresince 1sitılıp, ayarlanan sicaklıkta bekletilerek ergiyiğin kararlı hale gelmesi sağlanmaktadır.

Nexygen Davenport yazılımı EAİ değerinin yanında görünür viskozite değerini, görünür kayma hızını ve görünür kayma gerilmesini vermektedir. Elde edilen kayma hızı ve kayma gerilmesi ilişkisinden üs sabiti elde edilmektedir. Elde edilen bu üs sabiti değerleri kullanılarak görünür kayma hızı ve viskozite değerleri Rabinowitsch eşitliği ile düzeltilmektedir. Gerçekleştirilen deneylerde kullanılan yükler ve sıcaklık değerleri Tablo 1'de verilmiştir.

Tablo 1. Deneylerde kullanılan yük (basınç) ve sıcaklık değerleri (Load-pressure and temperature values used in the experiments)

\begin{tabular}{|c|c|c|}
\hline \multicolumn{2}{|c|}{ Uygulanan Yük } & Sicaklık \\
\hline$(\mathrm{kg})$ & $(\mathrm{kPa})$ & $\left({ }^{\circ} \mathrm{C}\right)$ \\
\hline 2,16 & 298,2 & 190 \\
\hline 3,80 & 524,0 & 200 \\
\hline 5,00 & 689,5 & 210 \\
\hline 7,16 & 987,4 & 220 \\
\hline
\end{tabular}

\section{DENEYSEL BULGULAR ve TARTIŞMA} (EXPERIMENTAL RESULTS AND DISCUSSION)

Ağırlıkça farklı oranlarda çinko boratın PP içerisine katılması ile elde edilmiştir. Çinko boratın dolgu maddesi olarak katılması hem plastik malzemenin maliyetlerini düşürecek hem de polipropilenin diğer fiziksel özelliklerini değiştirebilecektir. İçerisine katkı elemanı katılmış PP'nin endüstriyel ürüne dönüştürülebilmesi için kalıplanması gerekmektedir. Kalıplanarak ürün elde etme işlemi sırasında katkılı termoplastik malzeme ergitilerek kalıp içerisine belirli bir basınç, sıcaklık ve hız ile enjekte edilmektedir. Ergimiş termoplastiklerin viskoelastik akış özelliği gösterdiği bilinmektedir. Ancak, katkı maddesi ve katkı oranının ergimiş plastiğin akış özelliğini nasıl etkilediğinin bilinmesi hem kalıp tasarımcısı için hem de imalatçı için oldukça önemlidir.

Termoplastiklerin şekillendirilmesinde en çok kullanılan yöntemlerden olan enjeksiyonla kalıplama ve ektrüzyon ile şekillendirme yönteminde işleme parametreleri ergimiş plastiğin akış davranışına göre belirlenmektedir. Kalıp tasarımı yapılırken kalıp üzerindeki yolluk, dağıtıcı kanallar, giriş vb. elemanların yeri, boyutları ve sayısının bilinmesi gerekmektedir.
Akış analizi yapan simülasyon yazılımlarının doğru tahmin yapabilmesi için akış parametrelerinin de doğru girilmesi gerekmektedir. $\mathrm{Bu}$ parametreler; yoğunluk, ergime sıcaklığı, enjeksiyon/ektrüzyon işleme sıcaklığı, basınç, enjeksiyon hızı, camsı geçiş sıcaklığı ve viskozitesi gibi parametrelerdir. Katkısız plastiklerde bu parametreler hammadde üretici firmaları tarafında yaklaşık değerlerde verilebilmekte olup genellikle yazılım programlarının veri tabanında da bulunmaktadır. Ancak, içerisine dolgu/katkı maddesi, renklendirici, antioksidan, kararlaştırıcılar gibi maddeler eklendikten sonra plastiğin özelliklerinde nasıl bir değişism olduğunun bilinmesi gerekmektedir. Ayrıca, viskozitenin hesaplanması sırasında kullanılan bazı parametrelerin de bilinmesi oldukça önemlidir.

Viskozite, akış analizi sırasında yönetici eşitliklerde kullanılan en kritik parametrelerden biridir. Literatürde birçok viskozite modeli kullanılmaktadır. Akışkanın özelliğine ve akışın gerçekleştiği bölgeye göre bazı modeller başarılı bazı modeller ise başarısız sonuçlar elde edilmesine sebep olmaktadır. En yaygın olarak kullanilan Power Law, Carreau, Cross, Cross WLF modeli gibi yöntemlerdir. $\mathrm{Bu}$ modellerde kullanılan bazı parametrelerin deneysel olarak tespit edilmesi gerekmektedir. Bunlardan birisi de " $n$ " üstel fonksiyon değeridir. Newtonian akışlarda " $n$ " değeri 1, Newtonian olmayan akışlarda ise " $n$ " değeri 1'den farklıdır.

Gerçekleştirilen bu çalışmada PP içerisine ağırlıkça beş farklı oranda çinko borat ve \% 0,2 oranında antioksidan (Songnox 1010, Tetrakis [methylene-3(3,5-di-terbutyl-4-hydroxyphenyl) propionate] methane) maddesi katılmıştır. Elde edilen beş farklı kompozitin ve katkısız PP'nin ergiyik akış indeksi, viskozite, $n$ üstel fonksiyon değeri gibi parametrelerin katkı maddesi, katkı oranı, sıcaklık, basınç gibi parametrelerine bağlı olarak değişimi incelenmiştir. $\mathrm{Bu}$ bağlamda, farklı oranlarda çinko borat katkılı PP'nin kayma hızının üstel değeri olan ve akış davranış üssü olarak bilinen sabit sayıları (n) logaritmik kayma gerilmesi- logaritmik kayma hızı $(\log \tau$ ve $\log \gamma)$ grafiklerinde bulunan eğiminden elde edilmiştir (Tablo 2). Elde edilen bu $\mathrm{n}$ sabitlerinin çizelgede görüldüğü gibi oldukça yüksek bir $\mathrm{R}^{2}$ ile hesaplanmıştır. Tablo 2'de görüldüğü gibi n sabitinin artan sıcaklık değerine bağlı olarak arttığı tespit edilmiştir. Ayrıca, korelasyon katsayısının yüksek olmasına rağmen katkı oranının değişimine bağlı olarak $\mathrm{n}$ sabitinde anlamlı bir değişim tespit edilememiştir.

PP içerisine katılan çinko borat malzemesinin viskoziteyi nasıl etkilediğinin belirlenmesi amacıyla kayma hızı-kayma gerilmesi ilişkisinden " $n$ " üstel değerleri bulunmuştur. Bulunan " $n$ ” değerlerine bağlı olarak Rabonowich eşitliği kullanılarak görünür kayma hızı ve görünür kayma gerilmesi değerleri 
düzeltilmiştir. Düzeltilmiş kayma gerilmesi ve kayma hızından viskoziteler bulunmuştur. Şekil 1 ve Şekil 2' de Reoloji deney sonuçlarına göre $200{ }^{\circ} \mathrm{C}$ sıcaklık ve $298,2 \mathrm{kPa}$ basınç altında çinko borat katkı oranları; viskozite, ergiyik akış indeksi ve kayma hızı değişimleri verilmiştir.

Tablo 2. Çinko borat katkı oranları ve sıcaklık değişimine göre akış üssü değerleri (Flow index values according to zinc borate reinforced rate and temperature)

\begin{tabular}{|c|c|c|c|}
\hline $\begin{array}{c}\text { Çinko Borat } \\
\text { Katkı Oranı }(\%)\end{array}$ & $\begin{array}{c}\text { Sicaklık } \\
\left({ }^{\circ} \mathrm{C}\right)\end{array}$ & $\begin{array}{c}\text { Ak1ş Üssü } \\
\text { Sabiti (n) }\end{array}$ & $\mathrm{R}^{2}$ \\
\hline 0 & 190 & 0,582 & 0,999 \\
0 & 200 & 0,618 & 0,998 \\
0 & 210 & 0,620 & 0,997 \\
0 & 220 & 0,650 & 0,999 \\
\hline 5 & 190 & 0,586 & 0,997 \\
5 & 200 & 0,596 & 0,998 \\
5 & 210 & 0,614 & 0,997 \\
5 & 220 & 0,598 & 0,997 \\
\hline 7,5 & 190 & 0,595 & 0,998 \\
7,5 & 200 & 0,603 & 0,997 \\
7,5 & 210 & 0,621 & 0,998 \\
7,5 & 220 & 0,606 & 0,998 \\
\hline 11,25 & 190 & 0,612 & 0,998 \\
11,25 & 200 & 0,603 & 0,996 \\
11,25 & 210 & 0,627 & 0,999 \\
11,25 & 220 & 0,595 & 0,997 \\
\hline 16,875 & 190 & 0,595 & 0,999 \\
16,875 & 200 & 0,603 & 0,997 \\
16,875 & 210 & 0,610 & 0,998 \\
16,875 & 220 & 0,591 & 0,998 \\
\hline 25,3125 & 190 & 0,589 & 0,997 \\
25,3125 & 200 & 0,602 & 0,998 \\
25,3125 & 210 & 0,593 & 0,999 \\
25,3125 & 220 & 0,601 & 0,999 \\
\hline
\end{tabular}

Şekil 1'de görüldüğü gibi, çinko boratın PP içerisine katılması sonucu oluşan kompozitin viskozite değişimi artan katkı oranına göre artmıştır. Yaklaşık \%11,25'lik takviye oranına kadar viskozite değeri sürekli bir artmıştır. Ancak, çinko borat takviye oranı $\% 11,25$ den sonra ise viskozite değerinin düştüğü tespit edilmiștir. Ayrıca, sabit sıcaklıkta artan basınca göre de viskozitenin azaldığı belirlenmiştir. Uygulanan basınç ile ergimiş plastiğin daha kolay deforme edilebildiği ve molekül zincirlerinin akış doğrultusunda yönlendirildiği bu nedenle viskozitenin azaldığı düşünülmektedir.

Artan katkı maddesi oranına göre viskozitenin artışının tersine 298,2 kPa'lık sabit basınçta artan sıcaklık değerine göre viskozitenin azaldığ 1 Şekil 2'de görülmektedir. Böylece, çinko borat katkılı PP malzemesinin artan takviye oranına göre viskozitesinde \% 11,25 takviye oranından sonra biraz azalma olsa da genel olarak bir artış olduğu ancak, artan sıcaklık ve basınç ile viskozite değerinde azalma olduğu belirlenmiştir. Literatüre uygun olarak gerçekleşen bu deneysel çalışma sonucuna göre çinko borat takviye oranı yaklaşık \%11,25'e kadar arttığında viskozite değeri de artmaktadır. Kalıplama sırasında viskozitenin artması akışı zorlaştıracağı için diğer enjeksiyon parametrelerinin beraberinde artırılmasının gerekli olduğu anlaşılmaktadır.

Şekil 1 ve Şekil 2'de verilen çinko borat katkı oranına göre viskozite değişim grafiğine aksi şekilde Şekil 3'de görüldüğü gibi sabit sıcaklık altında ergiyik akış indeksi'nin artan takviye oranına göre azaldığı görülmüştür. Yine literatüre uygun olan bu durum takviye oranının molekül zincirleri arasında kalarak sürtünmeyi artırdığ 1 ve deformasyon oranını azalttığ 1 düşünülmektedir. Böylece, çinko borat takviyesinin akışa karşı gösterilen direnci artırdığı ve dolayısıyla birim zamanda orifisten geçen takviyeli PP miktarında azalmaya sebep olduğu bilinmektedir. Gerçekleştirilen bu deneysel çalışmada da viskozite artışı ve EAİ değerinin azalma yönünde gerçekleşmesi literatürdeki çalışmalara benzer doğrultuda gerçekleşmiştir. Sonuç olarak artan takviye oranına göre viskozite artışına ters olarak EAİ değerinde azalma olduğu tespit edilmiştir.

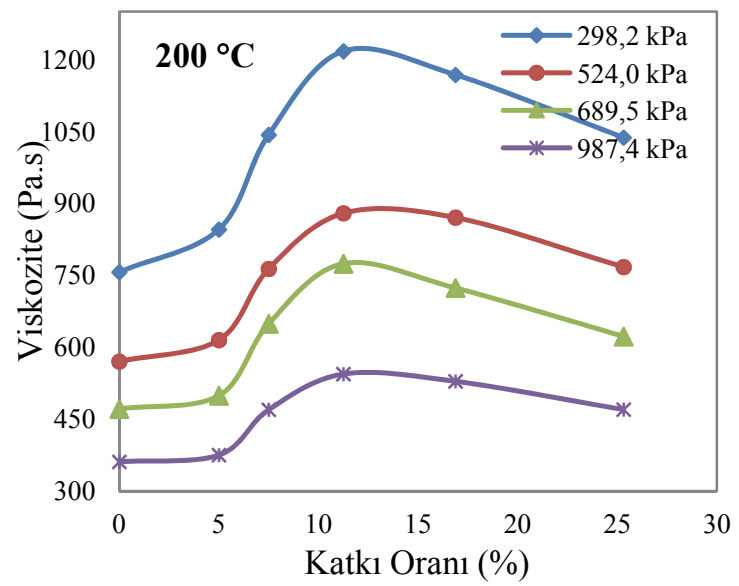

Şekil 1. $200{ }^{\circ} \mathrm{C}$ de çinko borat katkı oranları-viskozite değişimi (Variation of viscosity with rate of zinc borate additive at $200{ }^{\circ} \mathrm{C}$ )

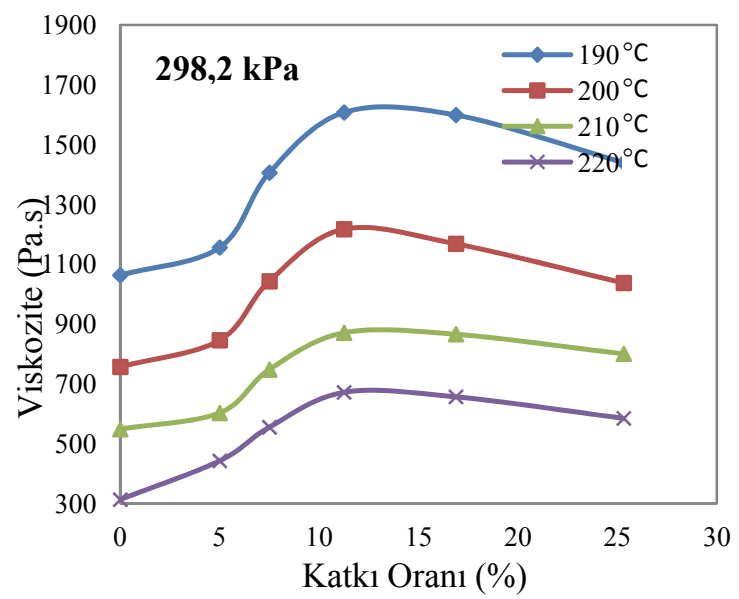

Şekil 2. $298,2 \mathrm{kPa}$ basınç altında çinko borat katkı oranları-viskozite değişimi (Variation of viscosity with rate of zinc borate additive at $298,2 \mathrm{kPa}$ pressure) 
Şekil 4'de sabit basınç altında EAİ'nin katkı oranı ve sıcaklık ile değişimi verilmiştir. $\mathrm{Bu}$ şekillerden anlaşılacağı gibi katkı oranı arttıkça EAİ değerinde azalma olduğu ancak sıcaklık artışına bağlı olarak EAİ değerinin arttığ 1 görülmektedir. Özellikle \% 11,625 değerine kadar EAİ'nin artan takviye oranı ile birlikte doğrusal olarak azaldığı daha sonra yaklaşık sabit kaldığı görülmektedir. Sıcaklık artışı PP'nin molekül bağlarını gevşettiği ve bağ açısının artmasına bağlı olarak deformasyonunun kolaylaşması neticesinde akışın artması sonucu 10 dakikada geçen ergimiş malzeme miktarında artış olduğu düşünülmektedir.

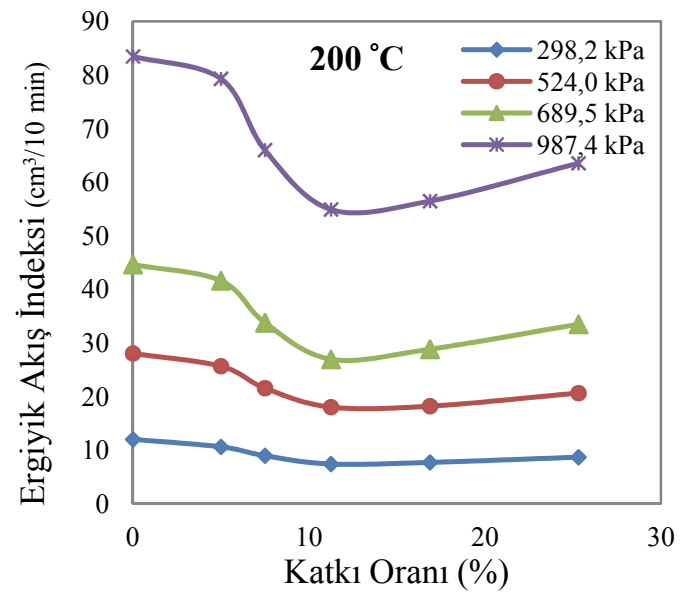

Şekil 3. $200{ }^{\circ} \mathrm{C}$ de çinko borat katkı oranları-ergiyik akış indeksi-EAİ değişimi (Variation of melt flow index-MFI with rate of zinc borate additive at $200{ }^{\circ} \mathrm{C}$ )

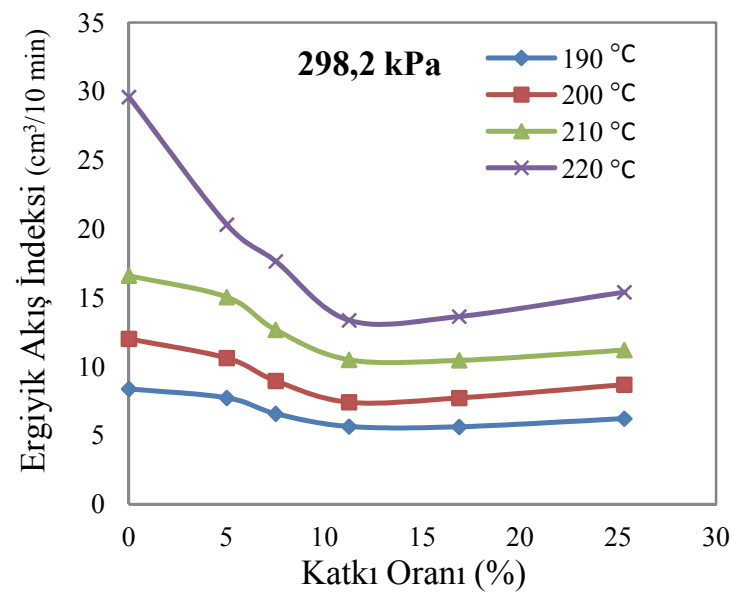

Şekil 4. 298,2 kPa basınç altında çinko borat katkı oranları-ergiyik akış indeksi-EAİ değişimi (Variation of melt flow index-MFI with rate of zinc borate additive at 298,2 kPa pressure)

Şekil 5'de sabit sıcaklık altında değişik basınçlarla yapılan deneysel çalışmada farklı oranlarda çinko borat katkılı PP'nin katk1 oran1-kayma hız1 değişimleri görülmektedir. Buradan anlaşılacağı gibi, katkı oranı arttıkça kayma hızının azaldığı, ancak artan basınç ile birlikte arttığı görülmektedir. Basıncın deformasyon hızı üzerindeki etkisinin açıkça görüldüğü bu grafik değerlerinin literatürdeki çalışmalara benzer sonuçlar verdiği tespit edilmiştir

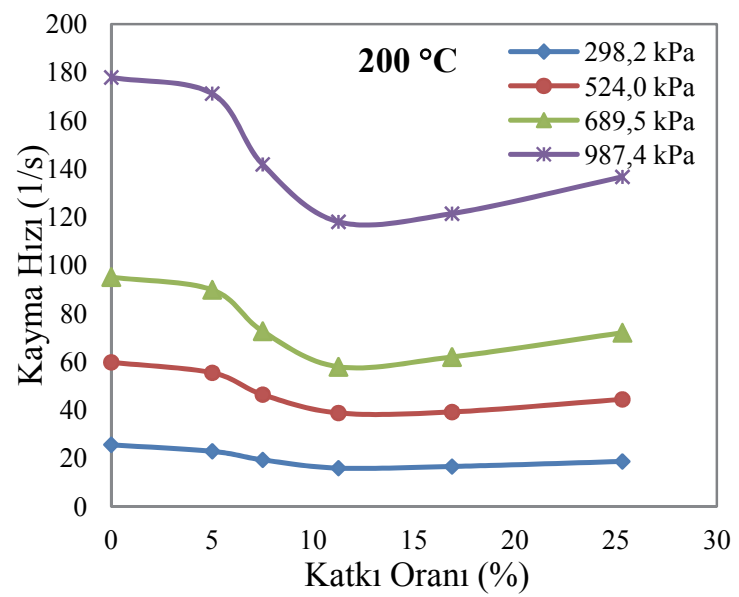

Şekil 5. $200{ }^{\circ} \mathrm{C}$ de çinko borat katkı oranları-kayma hızı değişimi (Variation of shear rate with rate of zinc borate additive at $200^{\circ} \mathrm{C}$ )

Şekil 6'da verilen grafikte kayma hızının artan katkı oranı ile azaldığ tespit edilmiştir. Katkı oranının makro moleküllü zincirlere sahip PP'nin deformasyonu sirasında sürtünme oluşturduğu veya bağ açlarının deformasyonuna engel teşkil ettiği böylece kayma hızını olumsuz etkilediği düşünülmektedir. Normal şartlarda bağ açısının zayıflaması ile ergimiş plastiğin deformasyonu yani akışı daha kolaylaşmaktadır. Ancak, molekül zincirleri arasına girmiş çinko borat parçacıkları molekül zincirlerinin hareketini kısıtladığı bunun da deformasyon oranını azalttığı düşünülmektedir.

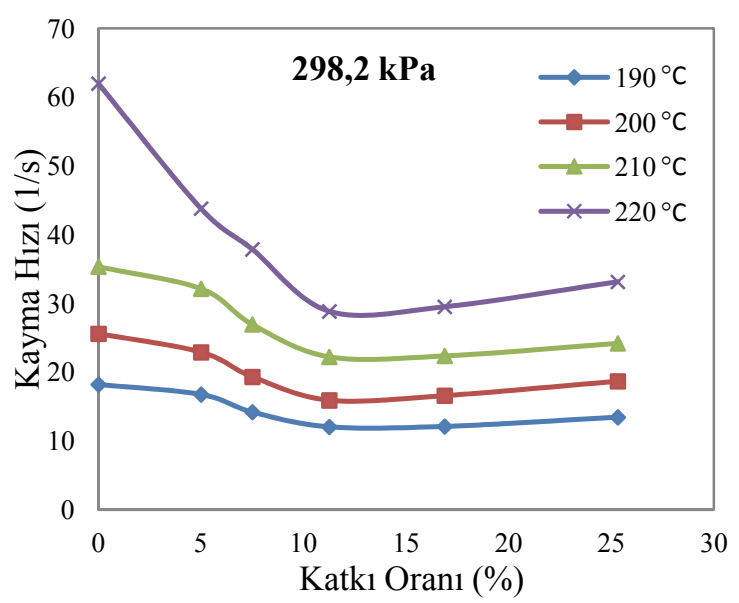

Şekil 6. $298,2 \mathrm{kPa}$ basınç altında çinko borat katkı oranları-kayma hızı değişim grafikleri (Variation of shear rate with rate of zinc borate additive at $298,2 \mathrm{kPa}$ pressure)

Şekil 7'de verilen grafiklere göre değişik oranlarda çinko borat katkılı PP'nin artan takviye oranına göre viskozite değerinin doğrusal olarak azaldığı ayrıca artan sıcaklık ile de arttığı tespit edilmiştir. Takviye elamanlarının molekül zincirleri arasında akışa engel olmasının ve molekül zincirlerinin deformasyonu 
sırasında arada kalıp deformasyon açısını azaltmasının etkili olduğu düşünülmektedir. Ayrıca, akış sırasında katkı elemanı partiküllerinin taşınırken bir enerji kaybına sebebiyet vermesinin de akışa engel olduğu ve böylece viskoziteyi düşürdüğü anlaşılmaktadır.

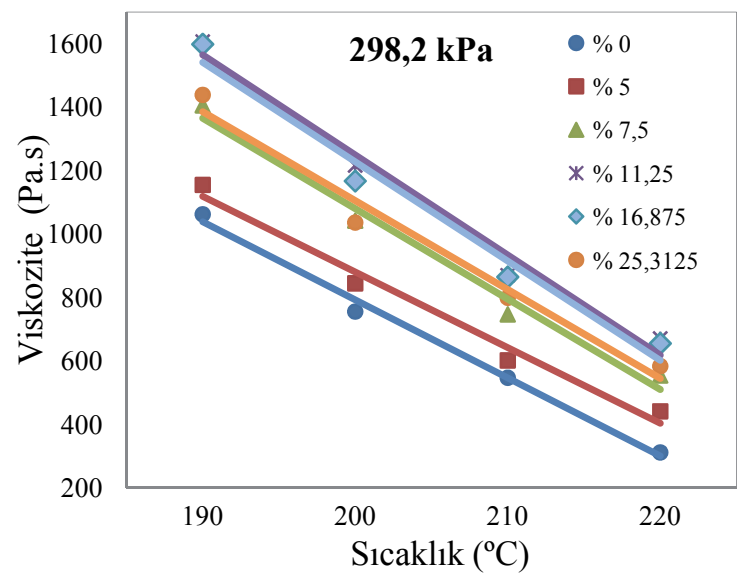

Şekil 7. $298,2 \mathrm{kPa}$ basınç altında sıcaklık-viskozite değișimi (Variation of temperature with rate of zinc borate additive at $298,2 \mathrm{kPa}$ pressure)

Kayma hızı ile viskozite değişimlerinin verildiği Şekil 8' de görüldüğü gibi, artan kayma hızı ile viskozitenin parabolik olarak azaldığı ayrıca, artan sıcaklık ile de viskozitenin azaldığı tespit edilmiştir. Kayma hızının artmasının makro moleküllerin akış doğrultusunda yönlendirilmesine yardımcı olduğu, karmaşık ve iç içe geçmiş molekül zincirlerinin düzlemselleşmesinin akışı kolaylaştırdığı ve böylece akışa karşı gösterilen iç direnç de düştüğü düşünülmektedir.

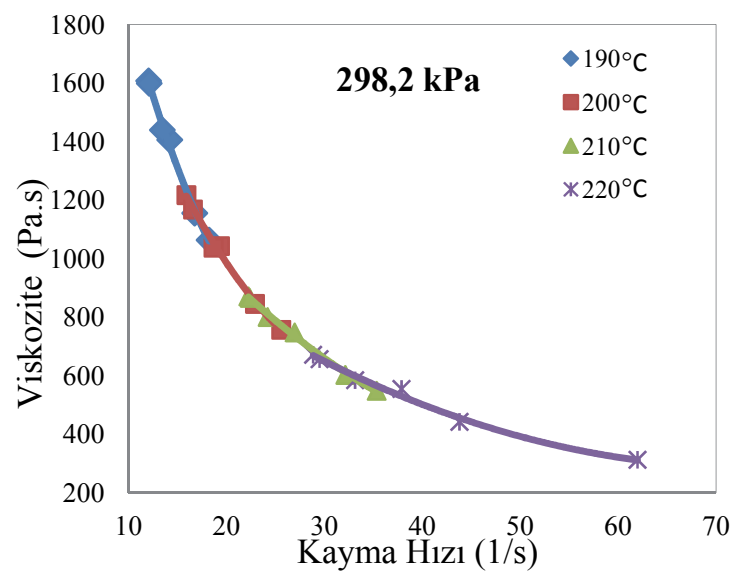

Şekil 8. $190{ }^{\circ} \mathrm{C}, 200{ }^{\circ} \mathrm{C}, 210^{\circ} \mathrm{C}$ ve $220^{\circ} \mathrm{C}$ sicaklıklar için 298,2 kPa basınç altında kayma hızı-viskozite değişimi (Variation of viscosity with shear rate at $298,2 \mathrm{kPa}$ pressure for temperatures of $190^{\circ} \mathrm{C}, 200^{\circ} \mathrm{C}, 210{ }^{\circ} \mathrm{C}$ and $220^{\circ} \mathrm{C}$ )

Kayma hızı ile viskozite değişimlerinin verildiği Şekil 9'da görüldüğü gibi, artan kayma hızı ile viskozitenin parabolik olarak azaldığı ayrıca, artan basınç ile de viskozitenin azaldığ 1 tespit edilmiştir. Kayma hızının artması makro moleküllerin akış doğrultusunda yönlendirilmesine yardımcı olduğu, karmaşık ve iç içe geçmiş molekül zincirlerinin düzlemselleşmesinin akışı kolaylaştırdığı ve böylece akışa karşı gösterilen iç direncin de düştüğü düşünülmektedir.

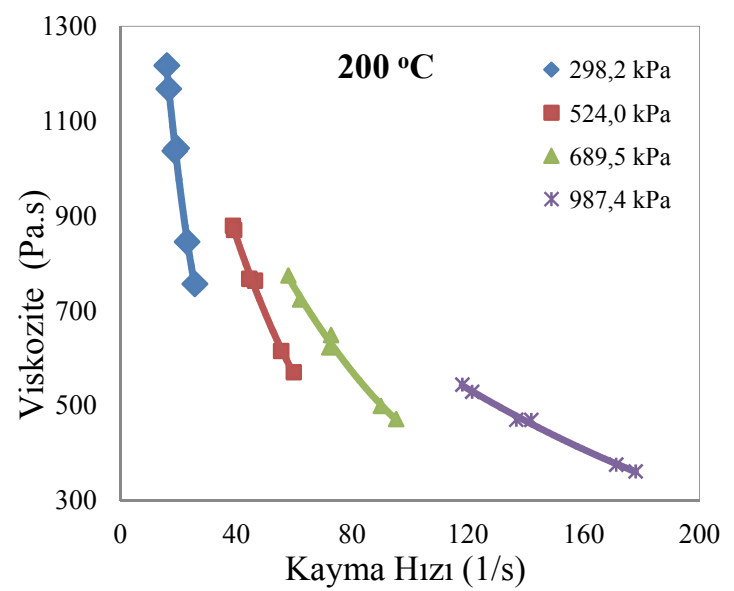

Şekil 9. $200{ }^{\circ} \mathrm{C}$ 'de kayma hızı-viskozite değişimi (Variation of viscosity with shear rate at $200^{\circ} \mathrm{C}$ )

EAİ'nin viskozitenin tersine kayma hızına bağlı olarak arttığı Şekil 10'dan anlaşılmaktadır. Ergimiş PP'nin moleküllerinin ve deformasyonun sicaklık ve basınç ile arttığı bilinmektedir. Bunun yanında, artan kayma hızı da akışı kolaylaştırdığı için EAİ değerinin artması beklenilen bir sonuçtur. Bu çalıșmada da literatüre uygun olarak kayma hızı arttıkça EAI değerinin de arttığı görülmüştür.

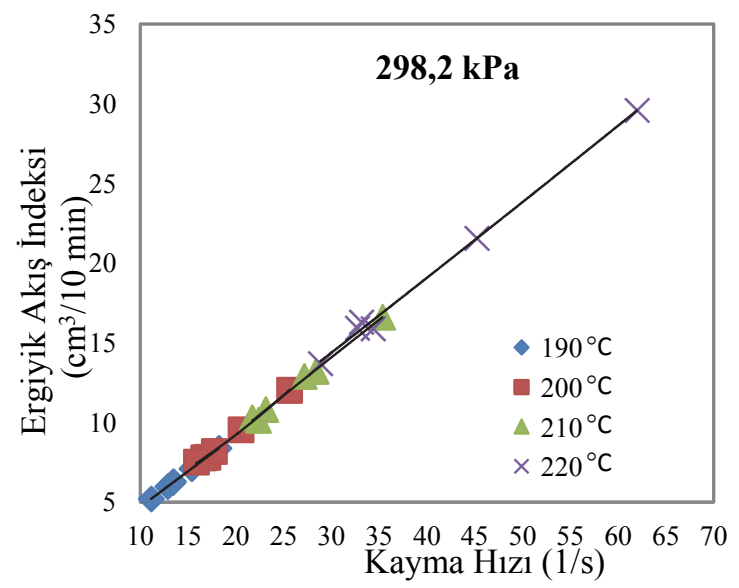

Şekil 10. $190{ }^{\circ} \mathrm{C}, 200{ }^{\circ} \mathrm{C}, 210{ }^{\circ} \mathrm{C}$ ve $220{ }^{\circ} \mathrm{C}$ için 298,2 $\mathrm{kPa}$ basınç altında kayma hızı-ergiyik akış indeksiEAİ değişimi (Variation of melt flow index-MFI with shear rate at $298,2 \mathrm{kPa}$ pressure for temperatures of $190{ }^{\circ} \mathrm{C}, 200^{\circ} \mathrm{C}, 210^{\circ} \mathrm{C}$ and $220^{\circ} \mathrm{C}$ )

EAI'nin sabit sıcaklıkta kayma hızına bağlı olarak arttığ1 Şekil 11'den anlaşılmaktadır. Ergimiş PP'nin moleküllerinin ve deformasyonun sıcaklık ve basınç

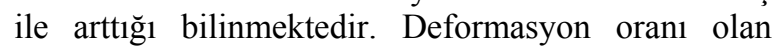
kayma hızının artması aynı zamanda akışkanlığın da artması anlamındadır. Gerçekleştirilen bu çalışmada, kayma hızı ile EAİ değişimi ilişkisi incelendiğinde EAİ'nin artan kayma hızına bağlı olarak doğrusal bir 
şekilde arttığ 1 görülmektedir. Literatürdeki çalışmalara uygun olan bu sonuca göre, kayma hızını arttıran basınç ve sıcaklık gibi parametrelerin EAİ değerini de artırdığı tespit edilmiştir. Makro moleküllü zincirlerden oluşan ergimiş PP moleküllerinin artan kayma hızı ile akış doğrultusunda yönlendirildiği böylece akışla karşı direnç oluşturan ve deformasyonu zorlaştırarak molekül zincirlerinin birbirleri üzerinde daha kolay kaydıkları düşünülmektedir. Bunun doğal sonucu olarak ta akış birim zamanda orifisten geçen akışkan miktarında da artışa sebep olmuştur.

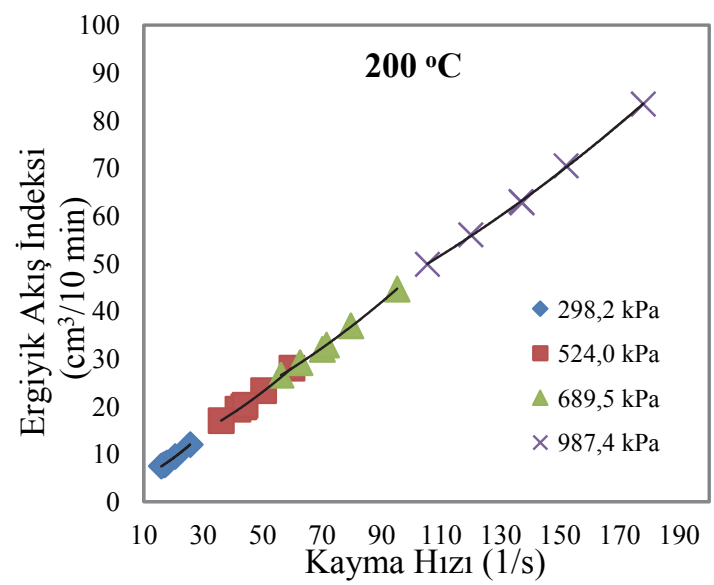

Şekil 11. 298,2 kPa, 524,0 kPa, 689,5 kPa ve 987,4 $\mathrm{kPa}$ basınç için $200{ }^{\circ} \mathrm{C}$ kayma hızı-ergiyik akış indeksi değişimi (Variation of melt flow index-MFI with shear rate at $200{ }^{\circ} \mathrm{C}$ for $298,2 \mathrm{kPa}, 524 \mathrm{kPa}, 689,5 \mathrm{kPa}$ and $987,4 \mathrm{kPa}$ pressure)

Şekil 12'de kayma hızı-kayma gerilmesi grafiği verilmiştir. Elde edilen grafiğin eğiminden akış üssü sabiti " $n$ " elde edilmektedir. Tablo 2 "de çinko borat katkı oranı ve sıcaklığa göre "n” değeri değişimleri verilmiştir. Buradan görüleceği gibi katkı oranı \% 11,25 'e kadar " $n$ " değeri artan katkı oranına bağlı olarak artmıştır. Ancak çinko borat katkı oranı \% 11,25 'den sonra ise artan katkı oranına bağlı olarak “n” değerinin azaldığı görülmektedir. Ayrıca, $220{ }^{\circ} \mathrm{C}$ hariç artan sıcaklığa bağlı olarak da " $n$ " değerinin artığ1 ancak $220{ }^{\circ} \mathrm{C}$ 'de ise azalma yönünde olduğu görülmektedir. "n” değeri kayma gerilmesi kayma hızı ilişkisinin eğimine eşit olduğu için " $n$ " değerinin artması kayma gerilmesi değerinin kayma hızına bağlı olarak daha yüksek oranda artması olarak değerlendirilmektedir.

Kayma gerilmesi akışkan üzerine uygulanan basıncı temsil etmektedir. Basinci temsil eden kayma gerilmesi arttıkça kayma hızının parabolik olarak artması, basıncın akışı parabolik bir ilişki şeklinde kolaylaştırdığı ve akışa olumlu etki ettiği tespit edilmiştir. Takviyeli plastiklerin akışının zor olduğu ve kalıp boşluğunun dolmadığı durumlarda basıncın artırılmasının çözümü kolaylaştıracağı anlaşılmaktadır. Şekil 13'de basınç-kayma hızı grafiği verilmiştir. Kayma gerilmesi basınca bağlı olarak hesaplandığı için basıncın etkisi de kayma gerilmesine benzer şekilde gerçekleşmiş olup, sabit sıcaklıkta basınç arttıkça kayma hızı parabolik olarak artmaktadır. Kayma hızının parabolik olarak artması, akışı kolaylaştırdığı ve akışa olumlu etki ettiği anlamına gelmektedir.

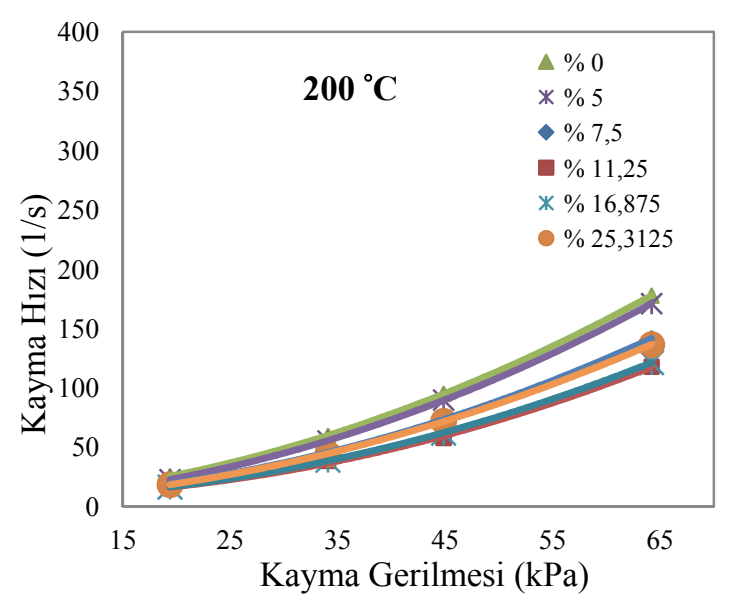

Şekil 12. $200{ }^{\circ} \mathrm{C}$ 'de kayma gerilmesi-kayma hızı değişimi (Variation of shear rate with Shear stress at $200{ }^{\circ} \mathrm{C}$ )

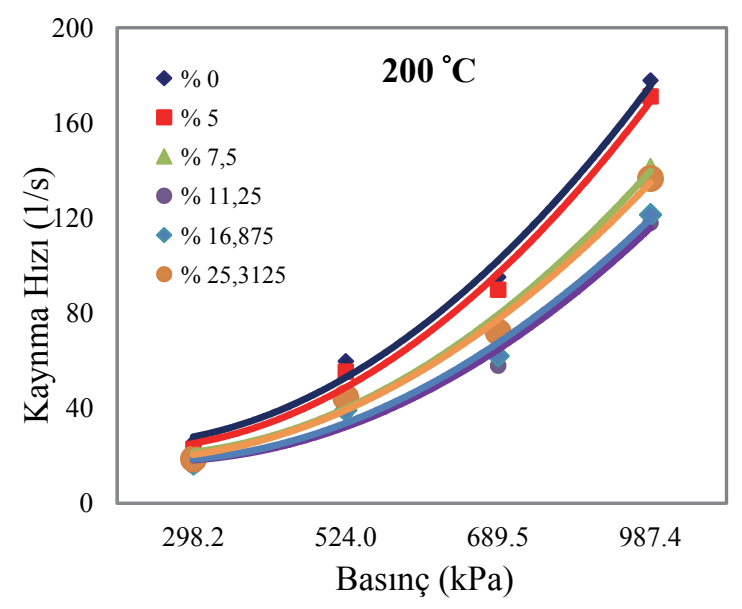

Şekil 13. $200{ }^{\circ} \mathrm{C}$ basınç-kayma hızı değişimi (Variation of shear rate with pressure at $200{ }^{\circ} \mathrm{C}$ )

\section{SONUÇ (CONCLUSION)}

Gerçekleştirilen bu çalışmada, ağırlıkça \% 5; \% 7,5; $\% 11,25 ; \% 16,875$ ve $\% 25,3125$ oranlarda çinko borat katkı maddesi ilave edilerek üretilmiş polipropilen malzemenin, reolojik özeliklerinin belirlenmesi için ergime akış indeksi testleri gerçekleştirilmiştir. Dört farklı yük ve dört farklı sıcaklık kullanılarak yapılan deneysel çalışmalarda aşağıdaki sonuçlar elde edilmiştir.

- Çinko borat tozunun PP içerisine katılmasıyla oluşan kompozitin viskozite değişimi artan katkı oranına göre artmıştır. Sabit sicaklıkta artan basınca göre de viskozitenin azaldığ 1 tespit edilmiștir. Artan katkı maddesi oranına göre viskozitedeki artışın tersine 298,2 kPa'lık sabit basınçta artan sıcaklık değerine göre viskozitenin 
azaldığı görülmektedir. Böylece, çinko borat katkılı PP malzemesinin artan takviye oranına göre viskozitesinde artış olduğu, ancak, artan sıcaklık ve basınç ile viskozite değerinde azalma olduğu görülmektedir.

- Sabit sıcaklık altında ergiyik akış indeksinde artan takviye oranına göre, viskozite artışına ters olarak azalma olduğu tespit edilmiştir. Katkı oranı arttıkça EAİ değerinde azalma olduğu ancak basınç ve sıcaklık artışına bağlı olarak EAİ değerinin arttığı da görülmektedir.

- Sabit sıcaklık altında değişik basınçlarla yapılan deneysel çalışmada farklı oranlarda çinko borat katkılı PP'nin katkı oranı arttıkça kayma hızının azaldığı, ancak artan basınç ve sıcaklık ile birlikte arttığ1 görülmektedir.

- Kayma hızı ile viskozite değişimleri; artan kayma hızı ile viskozitenin parabolik olarak azaldığ 1 ayrıca, artan basınç ve sıcaklık ile de viskozitenin azaldığı tespit edilmiştir.

- Ergimiş PP nin moleküllerinin ve deformasyonun sıcaklık ve basınç ile arttığı bilinmektedir. Yapılan deney sonuçlarında EAI'nin sabit basınç ve sıcaklıkta kayma hızına bağlı olarak arttığ görülmüştür.

- Sabit sıcaklıkta basınç arttıkça kayma hızı parabolik olarak artmaktadır. Kayma hızının parabolik olarak artması basıncın akışı kolaylaştırdığı ve akışa olumlu etki ettiği anlamına gelmektedir.

\section{TEŞEKKÜR (ACKNOWLEDGEMENT)}

$\mathrm{Bu}$ çalışmanın yapılmasında, proje kapsamında Gazi Üniversitesi Bilimsel Araştırma Merkezinden maddi destek alınmıştır. 07/2010-48 nolu proje ile desteğini esirgemeyen Gazi Üniversitesi yönetimine teşekkür ederiz.

\section{KAYNAKLAR (REFERENCES)}

1. Ting, C., Jian-Cheng, D., Long-Shuo, W., Gang, F.,"Preparation and characterization of nano-zinc borate by a new method", Journal of Materials Processing Technology, Cilt 209, 4076-4079, 2009.

2. Giúdice, C.A., Benytez, J.C., "Zinc borates as flame-retardant pigments in chlorine-containing coatings", Progress in Organic Coatings, Cilt 42, 82-88, 2001.

3. Garba, B., "Effect of zinc borate as flame retardant formulation on some tropical woods",
Polymer Degradation and Stability, Cilt 64, 517$522,1999$.

4. Antonietta, G., Robert, A.S., "Structural and thermal interpretation of the synergy and interactions between the fire retardants magnesium hydroxide and zinc borate", Polymer Degradation and Stability, Cilt 92, 2-13, 2007.

5. Fabien, C., Serge, B., Michel, L.B., Michel, F., "Charring of fire retarded ethylene vinyl acetate copolymer-magnesium hydroxide/zinc borate formulations", Polymer Degradation and Stability, Cilt 69, 83-92, 2000.

6. Durin-France, A., Ferry, L., J.M. Cuesta, L., Crespy , A., "Magnesium hydroxide/zinc borate/talc compositions as flame-retardants in EVA copolymer", Polymer International, Cilt 49, 1101-1105, 2000.

7. Köytepe, S.,Vural, S., Seçkin, T., "Molecular design of nanometric zinc borate-containing polyimide as a route to flame retardant materials", Materials Research Bulletin, Cilt 44, 369-376, 2009.

8. Kaully, T., Siegmann, A., Shacham, D., "Rheology of Highly Filled Natural $\mathrm{CaCO}_{3}$ Composites I. Effects of Solid Loading and Particle Size Distribution on Capillary Rheometry", Polymer Composites, Cilt 28, Say1 4, 512-523, 2007.

9. Carpentier, F., Bourbigot, S., Bras, M.L., Delobel, R., "Rheological investigations in fire retardancy: Application to ethylene--vinyl-acetate copolymermagnesium hydroxide/zinc borate formulations", Polymer International, Cilt 49, 1216-1221,2000.

10. Osswald, A.T., Polymer Processing Fundamentals, Hanser/Gardner Publications, Inc., Cincinnati, 1-139,1998.

11. Carreau, P.J., Kee, D.C.R.D., Chhabra, R.P., Rheology of polymeric system, Hanser/Gardner Publications, Cincinnati. 1-132, 1997.

12. Savaşçı, Ö.T., Uyanık, N., Akovalı, G., Ana hatları ile plastikler ve plastik teknolojisi, PAGEV Yayınları, İstanbul, 2002.

13. PETKIM, http://www.petkim.com.tr, 2012.

14. Nexygen Davenportplastik test yazılım kullanım klavuzu, Nexygen Davenport, 2002.

15. ASTM D 1238, Standart test method for melt flow rates of thermoplastics by extrusion plastomer, Annual Book of ASTM Standard, sayı 08.01, S 265-276, 2001.

16. TS EN ISO 1133, Plâstikler - Erimiş termoplastiklerin kütlesel akış hızının (MFR) ve hacimsel akış hızının (MVR) tayini, TSE, Ankara, 2011. 